\title{
INFLUENCE OF SOIL PHYSICAL AND CHEMICAL VARIABLES ON THE SPECIES COMPOSITION AND RICHNESS OF PLANTS IN THE ARID REGION OF TABUK, SAUDI ARABIA
}

\author{
KHALID AWADH AL-MUTAIRI
}

Biology Department, Faculty of Science, University of Tabuk, Tabuk 71491, Saudi Arabia; e-mail: kmutairi@ut.edu.sa

\begin{abstract}
Khalid A. Al-Mutairi: Influence of soil physical and chemical variables on species composition and richness of plants in the arid region of Tabuk, Saudi Arabia. Ekológia (Bratislava), Vol. 36, No. 2, p. 112-120, 2017.

The present study aims to investigate the effect of soil physical and chemical variables on the species richness and the floristic composition in four sites (Alwaz, Alqan, Sharma and Zetah) of Tabuk region in the Northwestern part of Arabian Peninsula. Only organic matter (OM), pH and calcium $(\mathrm{Ca})$ showed significant differences $(\mathrm{P}<0.05)$ amongst the four studied sites. Only magnesium and sodium were selected in the forward regression model and showed to be strong drivers of species richness of plants in Tabuk region (Adj- $\left.\mathrm{R}^{2}=0.438, \mathrm{~F} 2,13=6.85, \mathrm{P}=0.009\right)$. The multivariate analysis of canonical correspondence analysis (CCA) was applied to reveal the effect of the physical and chemical variables on the species composition of the plants. The CCA classifies the plant species into three groups based on their preference to the environmental variables. The first group of plant species (Group 1) is characterised by positive preference to the chloride (Cl) and negative relationship with $\mathrm{OM}$ and $\mathrm{pH}$. The second group (Group 2) is positively correlated with most of the soil variables such as $\mathrm{OM}$, calcium $(\mathrm{Ca})$, potassium $(\mathrm{K})$, bicarbonate $\left(\mathrm{HCO}_{3}\right)$, electrical conductivity (EC), sulphate $\left(\mathrm{SO}_{4}\right)$ and sodium $(\mathrm{Na})$. The third group (Group 3 ) has positive relationship with carbonate $\left(\mathrm{CO}_{3}\right)$ and negative relationship with $\mathrm{EC}$ and magnesium $(\mathrm{Mg})$. The chloride, sodium, sulphate, EC and carbonate are the main environmental factors influencing the plant species composition in Tabuk region. The cluster analysis based on the Euclidian measure shows that Alqan and Zetah have closer species composition compared to Sharma.
\end{abstract}

Key words: Tabuk, Arid Region, plant species, soil properties, environmental variables.

\section{Introduction}

It is well known that arid and semi-arid regions are vulnerable to landscape changes as well as other anthropogenic activities that have been recently increased due to fast development and urbanisation (Nicholson, Farrar, 1994; Nicholson et al., 1998; Evans, Geerken, 2004; Barakat et al., 2014; Hatim et al., 2016). The arid and semi-arid regions show interesting temporal variation in water availability and unique structure of floral communities (Snyder et al., 2004). There is a growing interest amongst ecologist to study the species composition of plants and the relative 
importance of spatial, environmental and soil factors (Jiang, 1993; Burke 2001; Solida et al., 2015; Agir et al., 2016). The emergence of quantitative techniques (such as ordination and clustering) in plant ecology had facilitated the understanding of the influence of environmental variables on plant species richness and composition (ter Braak, 1989; Zhang, F., Zhang, J., 2000).

As they constitute huge part of the world, deserts are an important part of the terrestrial environments. Despite that, little is known about the ecology of deserts and its flora compared to other terrestrial ecosystems (e.g. forests or grasslands). Therefore, the effect of biotic and abiotic factors on the plants species and richness in deserts still is not completely studied (Miriti et al., 2007; Bertiller et al., 2009; Bisigato et al., 2009; Wang et al., 2013; Wu, Yang, 2013; El-Ghani et al., 2012; Barakat et al., 2014; Shaltout et al., 2016).

Saudi Arabia has an area of approximately 2,026,213 $\mathrm{km}^{2}$ and that comprises almost twothirds of the Arabian Peninsula area. The dominant terrestrial ecosystem in Saudi Arabia is desert, which is characterised with low annual rainfall and elevated temperature, especially during summer time (can reach up to $50^{\circ} \mathrm{C}$ ) (Al-Nafie, 2008; El-Sheikh et al., 2013).

Although most of the Saudi Arabia is an arid region, it has considerably high diversity of plant species. A total of about 2,253 species in 132 families have been reported in this area, of which $20 \%$ are rare plants. Some of these plants are endemic to this region and show medical importance (Collenette, 1999). Based on the biogeography theory, the flora of Saudi Arabia has strong connections with that of North Africa, East Africa, the Mediterranean countries and the IranoTuranian countries (Alfarhan, 1999). Since 1970s, there is a significant change in the landscape of Saudi Arabia because of high rate of development, urbanisation and industrialisation (Khalik et al., 2013). Furthermore, less awareness of the importance of the natural biodiversity had been found amongst the people who can be another factor accounting for the remarkable deterioration in the flora of the Saudi Arabia (Al-Mutairi et al., 2015).

Several studies that aimed to study the influence of soil variables on the plant richness and species composition had been carried out in many arid regions of the Middle East such as Abd El-Ghani and Amer (2003). However, most ecologists have concentrated their studies on wadis drained in the Red Sea. For instance, some of these studies are Sharaf El-Din and Shaltout (1985) and Dargie and El-Demerdash (1991) (Wadi Araba) and Zareh and Fargali (1991) (Wadi AbuGhusun). On the other hand, very few studies have been carried out in the desert in the Arabian Peninsula to investigate the effect of soil variables on the plant species compositions. Most of the available studies described the vegetation cover, surveying the plant species and life forms (e.g. see Al-Mutairi et al., 2016).

The present study aims to investigate the soil environmental drivers of the plant species richness in four sites, Alwaz, Alqan, Sharma and Zetah of Tabuk region, which are situated in the Northern-east of Saudi Arabia. Furthermore, the study also aims to investigate the response of different plant species to soil variables.

\section{Material and methods}

\section{Study sites}

The present study was carried out in four sites, Sharma, Alqan, Alwaz Mountains and Alzetah, in Tabuk Province, Saudi Arabia (Fig. 1). The plant species were studied based on $10 \times 10 \mathrm{~m}$ stand. The stand was distributed randomly 


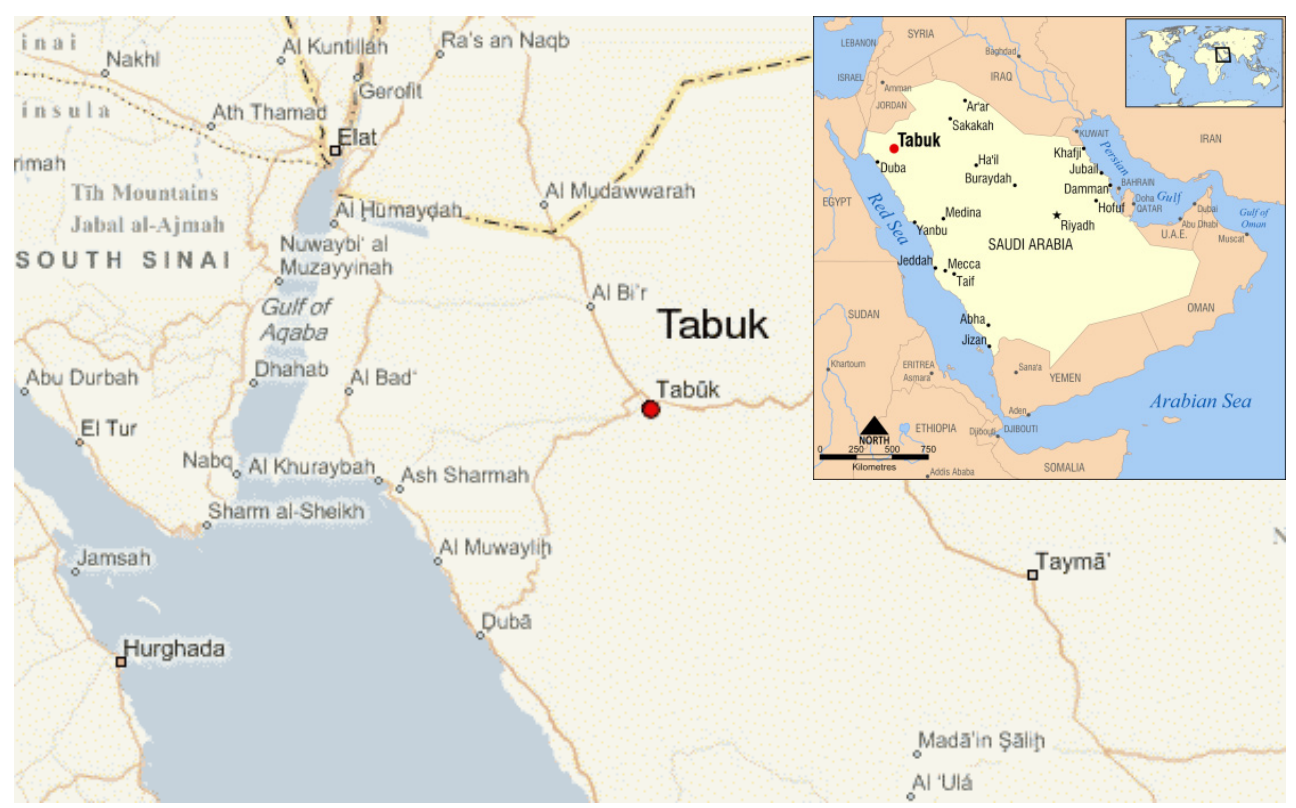

Fig. 1. The map of Tabuk, Saudi Arabia.

in each site. Then, the vascular plants found in the stand were recorded as present/absent. Identification of the plants was performed using the available keys of Chaudhary (2001) and Collenette (1999). Voucher of specimens were placed in the Herbarium of Faculty of Science, University of Tabuk. Further details about sampling and identification procedures can be found in our previous study (Al-Mutairi et al., 2016).

\section{Measuring the soil physical and chemical properties}

The physical and chemical variables of the soil in the selected sites were measured. In each stand, three sufficient amounts of soil sample were collected at a depth of $0-50 \mathrm{~cm}$ below the surface. The soil samples were placed in plastic bags, labelled and transferred to the laboratory. The soil extracts were prepared at a ratio of 1:5 in distilled water extract. This extract was used to measure the electrical conductivity (EC) and $\mathrm{pH}$. Furthermore, the soil samples were analysed for manganese $(\mathrm{Mn})$, organic matter $(\mathrm{OM})$, potassium $(\mathrm{K})$, sodium $(\mathrm{Na})$, magnesium $(\mathrm{Mg})$, calcium $(\mathrm{Ca})$, carbonate $\left(\mathrm{CO}_{3}\right)$, bicarbonate $\left(\mathrm{HCO}_{3}\right)$, sulphate $\left(\mathrm{SO}_{4}\right)$ and chloride $(\mathrm{Cl})$. Chlorides were determined by direct titration against silver nitrate solution using $5 \%$ potassium chromate as an indicator. The amount of soluble carbonates and bicarbonates were quantified by titration versus $0.01 \mathrm{~N} \mathrm{HCl}$, and sulphates were determined as barium sulphate using spectrophotometer at a wavelength of $500 \mathrm{~nm}$. Calcium and magnesium were determined using atomic absorption spectrophotometry. Meanwhile, sodium and potassium concentrations were estimated using flame photometer. All these procedures are outlined earlier by Jackson (1965) and Allen et al. (1986).

\section{Statistical analysis}

The collected data were analysed descriptively for the mean and standard error. The forward selection regression test was conducted between species richness against soil physical and chemical variables using R program (version 12.4.1) with the function $l m$ included in vegan package with two stopping criteria: Adj- $\mathrm{R}^{2}$ and $\mathrm{P}<0.05$. Canonical correspondence analysis (CCA) using CANOCO program (4.5 version) (ter Braak 1989) was applied to investigate the relationship between species composition and the soil variables. The amount of species variation explained by 
the soil variables, which also is known as the total variation explained (TVE), is defined as the sum of all eigenvalues divided by the total variation (TV) in the species data (Ohmann, Spies, 1998).

\section{Results}

The measured soil properties showed variation amongst the sites. The average values of the variables are shown in Table 1 . The $\mathrm{OM}, \mathrm{pH}$ and calcium $(\mathrm{Ca})$ showed significant differences (one-way analysis of variance (ANOVA), $\mathrm{P}<0.05$ ) amongst the four studied sites.

T a b l e 1. The soil physical and chemical variables (mean \pm SD) in Tabuk Region, Saudi Arabia.

\begin{tabular}{|l|c|c|c|c|c|}
\hline Variables & Alwaz & Alqan & Sharma & Zetah & $\begin{array}{c}\text { ANOVA } \\
\text { F3,12 }\end{array}$ \\
\hline Manganese $(\mathrm{Mn})$ & nd & $0.009 \pm 0.008$ & nd & $0.102 \pm 0.170$ & 1.349 \\
\hline Organic matter $(\mathrm{OM})$ & $0.100 \pm 0.074$ & $3.785 \pm 1.965$ & $2.143 \pm 0.649$ & $0.278 \pm 0.555$ & $10.520^{*}$ \\
\hline Electrical conductivity $(\mathrm{EC})$ & $0.240 \pm 0.041$ & $0.231 \pm 0.081$ & $0.171 \pm 0.044$ & $0.185 \pm 0.078$ & 1.129 \\
\hline $\mathrm{pH}$ & $7.853 \pm 0.081$ & $8.363 \pm 0.225$ & $8.278 \pm 0.195$ & $8.263 \pm 0.212$ & $5.963^{*}$ \\
\hline Potassium $(\mathrm{K})$ & $0.058 \pm 0.021$ & $0.050 \pm 0.015$ & $0.028 \pm 0.016$ & $0.046 \pm 0.024$ & 1.782 \\
\hline Sodium $(\mathrm{Na})$ & $0.072 \pm 0.053$ & $0.104 \pm 0.058$ & $0.031 \pm 0.021$ & $0.098 \pm 0.025$ & 2.441 \\
\hline Magnesium $(\mathrm{Mg})$ & $0.850 \pm 1.434$ & $0.095 \pm 0.034$ & $0.060 \pm 0.016$ & $0.060 \pm 0.016$ & 1.179 \\
\hline Calcium $(\mathrm{Ca})$ & $0.115 \pm 0.017$ & $0.150 \pm 0.038$ & $0.115 \pm 0.010$ & $0.095 \pm 0.010$ & $4.254^{*}$ \\
\hline Carbonate $\left.(\mathrm{CO})_{3}\right)$ & nd & $0.040 \pm 0.080$ & nd & nd & 1.000 \\
\hline Bicarbonate $\left(\mathrm{HCO}_{3}\right)$ & $0.158 \pm 0.051$ & $0.195 \pm 0.100$ & $0.120 \pm 0.016$ & $0.090 \pm 0.048$ & 2.206 \\
\hline Sulphate $\left(\mathrm{SO}_{4}\right)$ & $0.078 \pm 0.070$ & $0.075 \pm 0.024$ & $0.043 \pm 0.026$ & $0.164 \pm 0.080$ & 3.408 \\
\hline Chloride $(\mathrm{Cl})$ & $0.118 \pm 0.043$ & $0.083 \pm 0.048$ & $0.070 \pm 0.026$ & $0.045 \pm 0.010$ & 2.983 \\
\hline
\end{tabular}

The ANOVA results compared the means of the variables amongst the four studied sites. The significant differences $(\mathrm{P}<0.05)$ are marked with asterisk. $\mathrm{nd}=$ not detectable.

The selection procedures were applied to select the most important soil variables that may influence the species richness of plants. Surprisingly, amongst the 12 soil variables, only magnesium and sodium were selected in the regression model and showed to be the most important variables controlling the species richness of plants in Tabuk region (Adj-R2 $=0.438$, $\mathrm{F} 2,13=6.85, \mathrm{P}=0.009$ ).

Different soil variables were measured to examine the relationship between plant distribution and environmental variables. Figure 2 shows the diagram of CCA, a multivariate method to present the plant-environmental variables interaction. The total inertia stated by the CCA model was 5.444, and the sum of canonical eigenvalues was 4.149 . The amount of TVE by the environmental variables was $76.21 \%$. Interestingly, the plant species showed to respond to the soil variables accordingly. Three groups of plants based on their response to the soil variables were identified. The first group (Group 1) is known by its positive response against chloride $(\mathrm{Cl})$ and negative relationship with $\mathrm{OM}$ and $\mathrm{pH}$. Meanwhile, the second group (Group 2) showed to be positively correlated with most soil chemical and physical variables including $\mathrm{OM}$, calcium $(\mathrm{Ca})$, potassium $(\mathrm{K})$, bicarbonate $\left(\mathrm{HCO}_{3}\right)$, $\mathrm{EC}$, sulphate $\left(\mathrm{SO}_{4}\right)$ and sodium $(\mathrm{Na})$. Lastly, the third group of plant species is characterised by their preference 


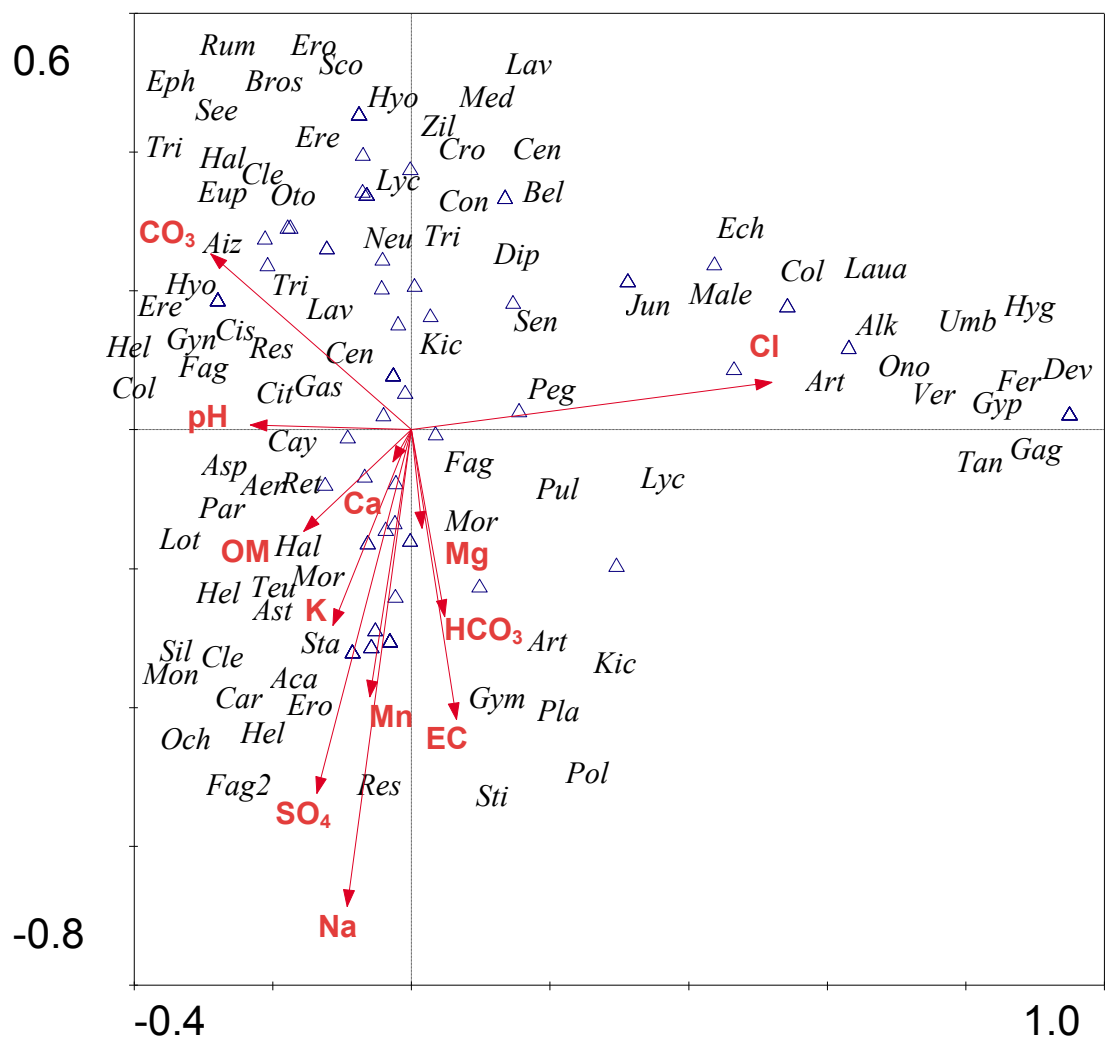

Fig. 2. Diagram of Canonical Correspondence Analysis (CCA) showing the relationship between soil variables and distribution of plants in Tabuk region.

to carbonate $\left(\mathrm{CO}_{3}\right)$ and negative relationship with EC and magnesium $(\mathrm{Mg})$. As indicated in the CCA model, the soil variables of chloride, sodium, sulphate, EC and carbonate were the most important factors controlling the community structure of plants in Tabuk region.

The cluster analysis based on the Euclidian measure shows that Alqan and Zetah have closer species composition compared to Alwaz. However, Sharma has different species composition (Fig. 3).

\section{Discussion}

In this study, a total of 96 species were reported from the studied four sites, and this number of species contributed to approximately $4 \%$ of the total number of species reported in Saudi Arabia. This number of species reported in this study is relatively higher from what has been reported from other deserts in Asia (Zhao et al., 2010; Zhang et al., 2016). 


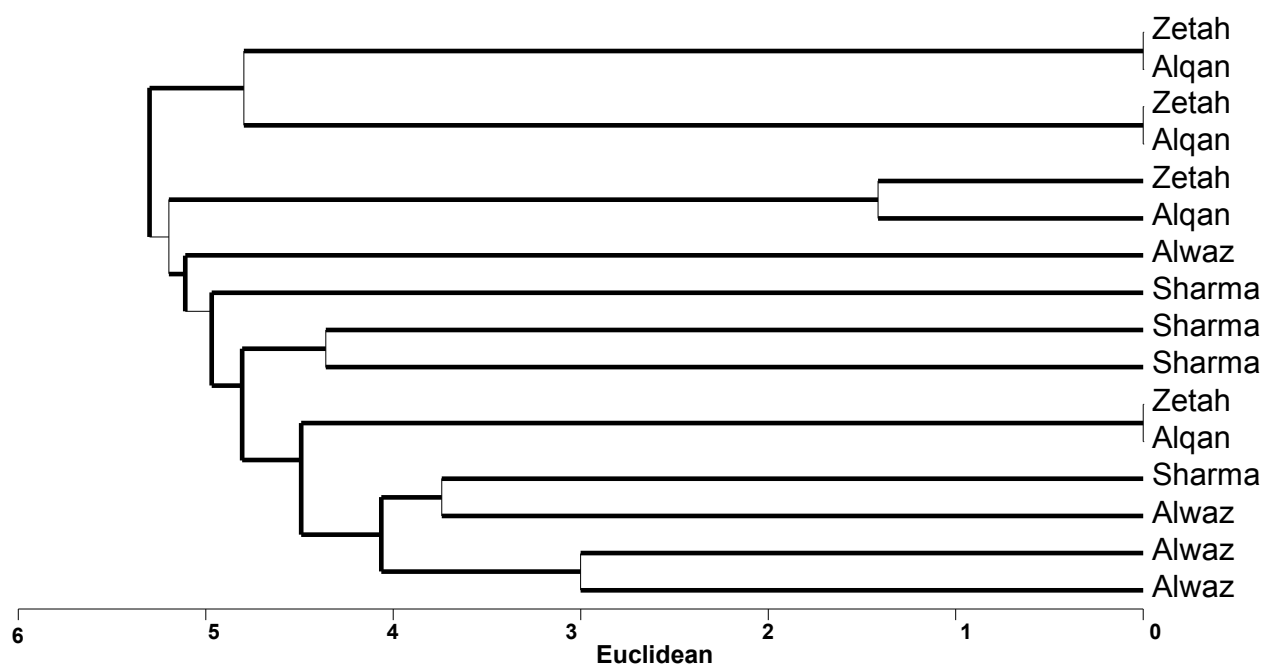

Fig. 3. The cluster analysis (based on the Euclidean distance) of the species composition amongst the four studies sites in Tabuk, Saudi Arabia.

In our previous study, it was shown that the highest number of species was reported in Alqan and Alzetah (Al-Mutairi et al., 2016). Based on the cluster analysis, Alqan and Zetah showed close pattern of species composition. However, Sharma showed unique species composition. Therefore, the attention should be directed to this area for further studies to investigate the habitats that contributed to remarkable special plant diversity.

According to Al-Mutairi et al. (2015), the plants in Tabuk region are under stress of different anthropogenic stressors, especially woodcutting. The plants have been continuously cut for heating and cooking purposes, especially during winter season. This is associated with remarkable deterioration in the plant diversity in this region.

In this study, the environmental variables such as $\mathrm{OM}$, soil $\mathrm{pH}$ and calcium showed significant differences amongst the study sites. This reflects the variance in the soil texture and OM inputs. The Alzetah and Alwaz are mountainous areas that experience falling of snow during winter time. However, Alqan and Sharma are near to coastal areas. This variation in the topography and climate is eventually associated with the variation in the soil characteristics. The OM profile would vary according to the habitat and the nitrogen and carbon inputs. Many researchers have suggested that microbial communities inhabiting soil play an important role in ecosystem carbon and nitrogen (e.g. Zak et al., 2003). It is assumed that variation in the OM amongst the sites is related to the microbial communities. However, the variation in the calcium profile and $\mathrm{pH}$ amongst the studied sites is probably related to the topography and the proximity of the site to the coastal areas.

Amongst the environmental variables, only magnesium and sodium were the strong variables that control the species richness in the studied area. The species richness is ex- 
pressed as the total number of species in each region (gamma diversity). Although many environmental variables were included in the regression model against the species richness, only magnesium and sodium showed significant relationship with species richness. This suggests that factors other than the abiotic environmental variables included in the analysis strongly influence the species richness. Possibly, the species richness in this region is controlled mainly by biotic interactions (e.g. competition). This is in agreement with the previous studies that found that only $50 \%$ of variation in the species diversity could be related to environmental variables (Galal, Fahmy, 2012).

The multivariate analysis of CCA was applied to determine the relationship between plant species and selected environmental variables. The TVE percentage of the CCA model was greater than $75 \%$, and this indicates that the studied variables could explain the variation in the species composition in this region. The multivariate CCA classified the plant species into three groups based on their preference to the different environmental variables. The environmental variables such as chloride, sodium, sulphate, EC and carbonate were identified as the key variables controlling the species composition in Tabuk region. In general, the important soil physical and chemical variables that are documented to be related to the distribution of plants are salinity, fertility (including nitrogen and phosphorus) and calcium carbonate (Shaltout, El-Sheikh, 1993; Shaltout et al., 1994; Al-Sodany, 1998).

\section{Conclusion}

In conclusion, the present study can be considered as the first effort investigating the effect of different environmental variables of the soil on the species richness and species composition of plants in Tabuk region at the North of Saudi Arabia. The species richness of plants showed to be related with magnesium and sodium, and this reflect the strength of the biotic factors such as competition in controlling the species richness in this region. This is an acceptable fact because in the arid region the nutrient resources might be limited with scarcity of water resources. Therefore, the plant species will undergo strong competition to obtain the nutrients and water. The multivariate analysis of CCA identified three groups of plant species that showed different preferences to the environmental variables. This reflects the strong variation in the tolerance and preference limits of the plant species because of the variation in the habitats and environmental settings. The Tabuk region has high diversity of plant species amongst which some are endemic. Therefore, programmes to conserve the plants in this region should be implemented. Previous reports showed that the woodcutting rate in this region is high, which may threaten the natural biodiversity of plants in this region. This urges application of intensive conservation programmes to increase the awareness amongst the residents towards the protection of natural flora.

\section{Acknowledgements}

I would like to express my sincere gratitude to the Faculty of Science at the University of Tabuk for facilitating the data collection and analysis. This study was supported by the Research Grant (s-0038-1436) provided by The Deanship of Scientific Research, University of Tabuk. 


\section{References}

Agır, S.U., Kutbay, H.G. \& Surmen B. (2016). Plant diversity along coastal dunes of the Black Sea (North of Turkey). Rendiconti Lincei, 27(3), 443-453. DOI: 10.1007/s12210-015-0497-z.

Alfarhan, A. (1999). A phytogeographical analysis of the floristic elements in Saudi Arabia. Pakistan Journal of Biological Sciences (Pakistan), 2(3), 702-711. DOI: 10.3923/pjbs.1999.702.711.

Allen, S. (1986). Chemical analysis. Oxford: Blackwell Scientific Publications.

Al-Mutairi, K.A., Al-Atawi, A., Alajlan, A. \& Al-Shami S.A. (2015). Woodcutting Activities in Tabuk Region (Saudi Arabia): assessment of conservation knowledge. Aceh International Journal of Science and Technology, 4(2), 54-58. DOI: 10.13170/aijst.4.2.2489.

Al-Mutairi, K., Al-Shami, S., Khorshid, Z. \& Moawed M. (2016). Floristic diversity of Tabuk Province, North Saudi Arabia. The Journal of Animal and Plant Sciences, 26(4), 1019-1025.

AlNafie, A.H. (2008). Phytogeography of Saudi Arabia. Saudi J. Biol. Sci., 15(1), 159-176.

Al-Sodany, Y.M. (1998). Vegetation analysis of canals, drains and lakes of northern part of Nile Delta Region. Ph.D. Thesis, Fac. Sci., Tanta Univ., Egypt.

Barakat, N.A.M., El-Gawad, A.M.A., Laudadio, V., Kabiel, H.F., Tufarelli, V. \& Cazzato E. (2014). A contribution to the ecology and floristic markers of plant associations in different habitats of Sinai Peninsula, Egypt. Rendiconti Lincei, 25(4), 479-490. DOI: 10.1007/s12210-014-0329-6.

Bertiller, M.B., Marone, L., Baldi, R. \& Ares J.O. (2009). Biological interactions at different spatial scales in the Monte desert of Argentina. J. Arid Environ., 73(2), 212-221. DOI: 10.1016/j.jaridenv.2007.08.008.

Bisigato, A.J., Villagra, P.E., Ares, J.O. \& Rossi B.E. (2009). Vegetation heterogeneity in Monte Desert ecosystems: a multiscale approach linking patterns and processes. J. Arid Environ., 73(2), 182-191. DOI: 10.1016/j.jaridenv.2008.09.001

Burke, A. (2001). Classification and ordination of plant communities of the Naukluft Mountains, Namibia. J. Veg. Sci., 12(1), 53-60. DOI: 10.1111/j.1654-1103.2001.tb02616.x.

Chaudhary, S.A. (2001). Flora of the Kingdom of Saudi Arabia. Riyadh: Ministry of Agriculture and Water.

Collentette, S. (1999). Wild flowers of Saudi Arabia. Riyadh: National Commission for Wildlife Conservation and Development.

Dargie, T. \& El Demerdash M. (1991). A quantitative study of vegetation-environment relationships in two Egyptian deserts. J. Veg. Sci., 2(1), 3-10. DOI: 10.2307/3235891.

El-Ghani, M.M.A. \& Amer W.M. (2003). Soil-vegetation relationships in a coastal desert plain of southern Sinai, Egypt. J. Arid Environ., 55(4), 607-628. DOI: 10.1016/S0140-1963(02)00318-X.

El-Ghani M.M.A., Shehata, M.N., Mobarak, A. \& Bakr R. (2012). Factors affecting the diversity and distribution of synanthropic vegetation in urban habitats of the Nile Delta, Egypt. Rendiconti Lincei, 23(4), 327-337. DOI: 10.1007/s12210012-0179-z.

El-Sheikh, M.A., Thomas, J., Alatar, A.A., Hegazy, A.K., Abbady, G.A., Alfarhan, A.H. \& Okla M.I. (2013) Vegetation of Thumamah Nature Park: a managed arid land site in Saudi Arabia. Rendiconti Lincei, 24(4), 349-367. DOI: 10.1007/ s12210-013-0246-0.

Evans, J. \& Geerken R. (2004). Discrimination between climate and human-induced dryland degradation. J. Arid Environ., $57(4), 535-554$

Galal, T.M. \& Fahmy A.G. (2012). Plant diversity and community structure of Wadi Gimal protected area, Red Sea Coast of Egypt. Afr. J. Ecol., 50(3), 266-276. DOI: 10.1111/j.1365-2028.2012.01320.x.

Hatim, M.Z., Shaltout, K.H., Schaminée, J.H., El-Kady, H.F., Janssen, J. \& El-Sheikh M.A. (2016). VegEgypt ecoinformatics: contribution to Sinai flora and vegetation. Rendiconti Lincei, 27(2), 383-399. DOI: 10.1007/s12210-015-0493-3.

Jackson, M. (1965). Soil chemical analysis. London: Constable, Ltd Co.

Jiang, H., Huang, J., Chen, L., Yang, Z. \& Yang X. (1993). DCA ordination, quantitative classification and environmental interpretation of plant communities in Dongling Mountain. Acta Bot. Sin., 36(7), 539-551.

Khalik, K.A., El-Sheikh, M. \& El-Aidarous A. (2013). Floristic diversity and vegetation analysis of Wadi Al-Noman, Mecca, Saudi Arabia. Turk. J. Bot., 37(5), 894-907. DOI: 10.3906/bot-1209-56.

Miriti, M.N., Rodríguez-Buriticá, S., Wright, S.J. \& Howe H.F. (2007). Episodic death across species of desert shrubs. Ecology, 88(1), 32-36. DOI: 10.1890/0012-9658(2007)88[32:EDASOD]2.0.CO;2.

Nicholson, S. \& Farrar T. (1994). The influence of soil type on the relationships between NDVI, rainfall, and soil moisture in semiarid Botswana. I. NDVI response to rainfall. Remote Sens. Environ., 50(2), 107-120. DOI: 10.1016/00344257(94)90038-8.

Nicholson, S.E., Tucker, C.J. \& Ba M. (1998). Desertification, drought, and surface vegetation: An exam- 
ple from the West African Sahel. Bulletin of the American Meteorological Society, 79(5), 815-829. DOI: 10.1175/1520-0477(1998)079<0815:DDASVA>2.0.CO;2.

Ohmann, J.L. \& Spies T.A. (1998). Regional gradient analysis and spatial pattern of woody plant communities of Oregon forests. Ecol. Monogr., 68(2), 151-182. DOI: 10.1890/0012-9615(1998)068[0151:RGAASP]2.0.CO;2.

Shaltout, K. \& El-Sheikh M. (1993). Vegetation-environment relations along water courses in the Nile Delta region. J. Veg. Sci., 4(4), 567-570. DOI: 10.2307/3236085.

Shaltout, K., El-Din, A.S. \& El-Sheikh M. (1994). Species richness and phenology of vegetation along irrigation canals and drains in the Nile Delta, Egypt. Vegetatio, 112(1), 35-43. http://www.jstor.org/stable/20046420

Shaltout, K.H., Farahat, E.A. \& Shalapy A.I. (2016). Effect of a desert planted forest on the understory plant diversity: implication to conservation. Rendiconti Lincei, 27(4), 711-719. DOI: 10.1007/s12210-016-0553-3.

Sharaf-El-Din, A. \& Shaltout K. (1985). On the phytosociology of Wadi Araba in the Eastern Desert of Egypt. Proceedings of Egyptian Botanical Society, 4, 1311-1325.

Snyder, K., Cable, J., Huxman, T. \& Tartowski S. (2004) Arid ecosystem responses to variations in the frequency and magnitude of growing season precipitation. 89th Annual Meeting, Ecological Society of America.

Solida, L., De Nicola, C., Fanfani, A., Jacomini, C., Licitra, V. \& Testi A. (2015). Multi-set indicators to assess environmental quality using soil microarthropods, plants and humus. Rendiconti Lincei, 26(Suppl. 3), 561-569. DOI: 10.1007/s12210-014-0337-6.

ter Braak, C.J. (1989). CANOCO-an extension of DECORANA to analyze species-environment relationships. Hydrobiologia, 184(3), 169-170. DOI: 10.1007/BF02392953.

Wang, Y., Yang, X. \& Shi Z. (2013). The formation of the patterns of desert shrub communities on the Western Ordos Plateau, China: the roles of seed dispersal and sand burial. PloS one, 8(7), e69970. DOI: 10.1371/journal. pone.0069970.

Wu, B. \& Yang H. (2013). Spatial patterns and natural recruitment of native shrubs in a semi-arid sandy land. PloS one, 8(3), e58331. DOI: 10.1371/journal.pone.0058331

Zak, D.R., Holmes, W.E., White, D.C., Peacock, A.D. \& Tilman D. (2003) Plant diversity, soil microbial communities, and ecosystem function: are there any links? Ecology, 84(8), 2042-2050. DOI: 10.1890/02-0433.

Zareh, M. \& Fargali K. (1991). Vegetation of inland desert wadies in Egypt. Feddes Repert., 102(7-8), 647-656. DOI: 10.1002/fedr.19911020716.

Zhang, F. \& Zhang J-t. (2000). Research progress of numerical classification and ordination of vegetation in China. Journal-Shanxi University Natural Science Edition, 23(3), 278-282.

Zhang, R., Liu, T., Zhang, J.-L. \& Sun Q.-M. (2016). Spatial and environmental determinants of plant species diversity in a temperate desert. Journal of Plant Ecology, 9(2), 124-131. DOI: 10.1093/jpe/rtv053.

Zhao, H., Tong, L., JiaQiang, L., DongWei, G. \& XinJun Z. (2010). $\beta$ Diversity characteristic of vegetation community on south part of Gurbantunggut Desert and its interpretation. Acta Prataculturae Sinica, 19(3), 29-37. 